\title{
RAKONTE MWEN: UM PROJETO DE ENSINO DO PORTUGUÊS BRASILEIRO A IMIGRANTES HAITIANOS A PARTIR DA LITERATURA POPULAR
}

\author{
Rakonte Mwen: Brazilian Portuguese teaching project for Haitian immigrants \\ based on popular literature
}

\author{
Laura Fontana SOARES, UFFS ${ }^{1}$ \\ Larissa Paula TIRLONI, UFPR/UNILA ${ }^{2}$
}

\begin{abstract}
RESUMO: Apesar do crescimento no ensino de português como língua não materna, há pouco material didático voltado às necessidades dos aprendizes pertencentes aos novos afluxos migratórios, no qual se inserem os imigrantes haitianos. Em tal contexto, este artigo apresenta a aplicação do Projeto de Contação de Histórias (PCH) Rakonte Mwen, "conta pra mim" em crioulo haitiano, uma proposta de ensino do português brasileiro, alicerçada pela literatura popular haitiana e brasileira. Para tanto, utilizamos o método intervencionista da pesquisa-ação no planejamento das atividades e avaliação dos resultados, além da Pedagogia de Projetos como metodologia didática. A abordagem intercultural no ensino de línguas, bem como o conceito de Língua de Acolhimento, nortearam a ação pedagógica. Através dos resultados, sustentamos que o ensino baseado em projetos e centrado na abordagem intercultural é producente no trabalho com línguas para imigrantes em situação similar a de refugiados. Desse modo, a perspectiva de acolhimento a partir da literatura popular permite a difusão da cultura dos novos imigrantes e a inserção desse grupo no Brasil, suscitando um novo olhar sobre o aprendizado da língua portuguesa. Também refletimos sobre o papel docente no ensino de uma Língua de Acolhimento, perspectiva para a construção de novas práticas educacionais.
\end{abstract}

PALAVRAS-CHAVE: Abordagem intercultural; Língua de Acolhimento; Pedagogia de Projetos.

ABSTRACT: Despite the growth in teaching Portuguese as a foreign language there is little teaching material designed to help new immigrants like the Haitians. In this context, this paper presents the application of a project named "Tell Me a Story", originally Projeto de Contação de Histórias ( $\mathrm{PCH}$ ) Rakonte Mwen, a Brazilian Portuguese teaching proposal, based on Haitian's and Brazilian's short stories. It was employed the interventionist method of action research in the activity planning and results evaluation, besides the Pedagogy Project as the didactic method. The pedagogical action has been guided by the intercultural approach to language teaching and the concept of "Shelter Language". Based on the results, we argue that the teaching based on the Project Based Learning and concerned with the intercultural approach productive when working with languages for immigrants in situations similar to refugees. Thus, the act of teaching

\footnotetext{
${ }^{1}$ Graduanda do curso de Letras Português e Espanhol. 1.fontanasoares@gmail.com

${ }^{2}$ Professora de Língua Espanhola e Língua Portuguesa Adicional na Universidade Federal da Integração Latino-Americana. Doutoranda em Letras pela Universidade Federal do Paraná. larissa.tirloni@unila.edu.br
} 
Portuguese through popular literature allows the cultural promotion to these new immigrants, giving them a new perspective of the Portuguese language. The results also provide reflections about the teacher's role in the work with the welcoming language, a perspective from which is possible to develop new educational practices.

KEYWORDS: Intercultural approach; Pedagogy Projects; Welcoming Language.

\section{INTRODUÇÃO}

A aprendizagem do português como língua estrangeira é condicionada por questões subjacentes, como a finalidade pela qual o imigrante se encontra no país, condição e tempo de permanência, além do grau de escolaridade. Apesar do crescimento no ensino e na pesquisa da língua majoritária do Brasil como não-materna, há um lapso no que se refere ao português como Língua de Acolhimento, conceito que, segundo Grosso (2010, p.68), "ultrapassa a noção de língua estrangeira ou de língua segunda", direcionado àqueles estrangeiros que chegam ao país com dificuldades financeiras e psicológicas devido à condição de refúgio ou asilo humanitário (AMADO, 2013).

Dada a crescente dinâmica de migração haitiana, há material de ensino do português destinado ao referido público, como a apostila Língua portuguesa para haitianos, de Pimentel et al.(2014), e Pode entrar: português do Brasil para refugiadas e refugiados, material lançado em 2015 pela Agência da ONU para Refugiados (ACNUR). No entanto, o ensino de língua portuguesa na perspectiva de acolhimento é um conceito recente que demanda discussão e pesquisa, inicialmente abordado em relação ao português lusófono por autoras como Ança (2003) e Cabete (2010). No tocante ao português brasileiro, destacam-se as pesquisas de Amado (2013), Ruano e Grahl (2015), além do projeto Português Brasileiro para Migração Humanitária- PBMIH da Universidade Federal do Paraná, que trabalha com o conceito de língua de acolhimento (RUANO; CURSINO, 2015).

Por esse prisma, o presente trabalho configura-se como uma proposta de ensino de língua portuguesa, através da criação e aplicação de um Projeto de Contação de Histórias, a partir do gênero literário conto popular, para imigrantes haitianos. O produto final proposto consiste em um blog que compila as produções orais e escritas dos estudantes no intuito de divulgar a cultura haitiana aos brasileiros. No ensino de uma Língua de Acolhimento, destacamos como producente o trabalho com os aspectos 
identitários, o que nos leva à hipótese de que o ensino baseado na abordagem intercultural, com enfoque na literatura, possibilita perspectiva de compreensão e inserção de um sujeito no país que o acolhe.

As etapas do trabalho baseiam-se na Pedagogia de Projetos, em conformidade aos conceitos de Camps (1996). A metodologia da pesquisa-ação educacional permite identificar um ponto a ser melhorado na prática docente para, em seguida, planejar uma ação, acompanhar e avaliar os resultados; em relação a este conceito, baseamo-nos em David Tripp (2005). Para efetivar a proposta do ensino do português brasileiro com perspectiva intercultural (MENDES, 2004), pautamo-nos em atividades que abarcam o entendimento linguístico por meio da produção e recepção oral e escrita na língua alvo (SOLÉ, 1998). A aplicação se deu no curso "Português para Estrangeiros", projeto de extensão que atende aos haitianos acadêmicos da Universidade Federal da Fronteira Sul (UFFS), campus ChapecólSC, além daqueles pertencentes à comunidade externa.

A fim de situar o leitor, primeiramente trazemos a contextualização sobre a proposta de ensino e a abordagem teórica do ensino intercultural atrelado à literatura. Em seguida, apresentamos o Projeto de Contação de Histórias Rakonte Mwen, "conta pra mim”, sua aplicação e a análise tecida a partir dos resultados. Concomitantemente, refletimos sobre o papel do professor em um projeto de ensino acolhedor e intercultural. Por fim, sistematizamos os resultados obtidos em relação ao referido projeto de ensino.

\section{A LITERATURA COMO EIXO ESTRUTURANTE DO PROJETO COM PERSPECTIVA DE ENSINO INTERCULTURAL}

$\mathrm{Na}$ abordagem de ensino intercultural é necessário definir o que é cultura. Edleise Mendes (2004) relembra que muitos são os casos em que um conjunto de estereótipos e características estanques de um povo/nação é tomado como matéria para o ensino intercultural, prejudicando o real intento da abordagem em questão. Consideramos, assim como a autora, que a delimitação das questões culturais não é tarefa simples, contudo, optamos por viabilizar o ensino intercultural do português brasileiro a imigrantes haitianos através da literatura popular, mais especificamente do gênero conto 
popular. Com a definição deste tema norteador, centrado no gênero conto popular ${ }^{3}$, todas as atividades interligam-se com a finalidade da construção de um blog como produto final. Para justificar o enfoque literário, fundamentamo-nos no conceito de literatura como manifestação cultural.

No entendimento do teórico Antonio Candido (2002), a literatura exerce função psicológica relevante na vida do homem, de ficção e fantasia. Segundo o autor:

\begin{abstract}
A literatura propriamente dita é uma das modalidades que funcionam como resposta a essa necessidade universal, cujas formas mais humildes e espontâneas de satisfação talvez sejam coisas como a anedota, a adivinha, o trocadilho, o rifão. Em nível complexo surgem as narrativas populares, os cantos folclóricos, as lendas, os mitos. (CANDIDO, 2002, p.83)
\end{abstract}

Com base nesta assertiva, a literatura desempenha papel de afirmação identitária, por comportar elementos culturais de um povo, mas sem se limitar a esta função. Dessa forma, os contos populares não se encerram no espelhamento de características de um povo/nação, pois são elementos complexos, condensadores de lampejos culturais diversos, autônomos em seu significado, mas “(...) esta autonomia não a desliga das suas fontes de inspiração no real, nem anula a sua capacidade de atuar sobre ele" (CANDIDO, 2002, p.86). Não temos a pretensão de afirmar que a literatura retrata uma cultura, contudo, como pontua Mendes (2004, p.101), cultura é "uma dimensão do humano que se alimenta e se renova constantemente, e que absorve, em maior ou menor grau, as marcas de um viver e fazer social particulares".

A partir da definição de literatura como expressão cultural, defendemos a presença de uma heterogeneidade de crenças e de concepções de mundo, em que uma não se sobrepõe a outra, ao conciliar a cultura brasileira e a haitiana. Sá (2014) retoma as ideias dos "não-lugares", do antropólogo Marc Augé, e relembra que o apagamento cultural dos sujeitos é reforçado pelos centros urbanos, minados de informações em excesso e de lugares comuns, não familiares, que atuam como propulsores da perda da identidade individual. Por esse viés, defendemos a importância de preservar e conhecer a cultura haitiana: o imigrante encontra-se "desterritorializado", propenso a ter sua cultura suprimida, principalmente quando esta provém de países socialmente estigmatizados

\footnotetext{
${ }^{3}$ Julgamos que o trabalho a partir de um gênero discursivo seria produtivo também pelo viés do Interacionismo sócio-discursivo. Consideramos a futura aplicação desta abordagem para novas sequências didáticas no ensino do português para imigrantes haitianos.
} 
como o Haiti, logo, a voz desses sujeitos deve ser ouvida para que os brasileiros conheçam mais sobre o país dos imigrantes, estabelecendo relação de alteridade.

Por esse prisma, "a cidade dos indivíduos é o mundo onde cada um mantém relação com o lugar a partir da memória, do cotidiano, das experiências vividas. A identificação de cada pessoa com um lugar sobressai dessa ligação forte com um território" (SÁ, 2014, p.222). Compreendemos, assim, os imigrantes haitianos como sujeitos apartados abruptamente de seus ambientes familiares, incapazes de estabelecer relações com lugares incompreendidos culturalmente, com os quais não se identificam pela ausência de um espaço para expor sua identidade, tampouco para assimilar aquela que se contrapõe. Na perspectiva de sujeito desterritorializado, imigrante e refugiado, pensamos a literatura haitiana como forma de afirmação do indivíduo que assume seu papel de sujeito socialmente atuante, justificando, assim uma abordagem de ensino intercultural.

\section{LITERATURA HAITIANA}

A obra País Sem Chapéu (2011), de Dany Laferrière, é um exemplo de produção literária haitiana. Apesar de não se tratar de literatura popular, o texto expande seu conteúdo ao fecundo universo de crenças que caracterizam o país de origem do autor, o Haiti, repleto de referências à religião vodu, espaços geográficos da capital do país e à língua materna da maioria da população. Segundo Heloisa Moreira, tradutora e autora do posfácio do livro de Laferrière, a leitura da obra revela nuances culturais do Haiti, muitas vezes desconhecidas pelos brasileiros, pois "diante das informações que chegam até aqui, parece uma utopia falar em literatura haitiana" (2011, p.219). A produção literária haitiana, no quadro mundial, ainda é pouco difundida, fato que se deve à invisibilidade do país caribenho. Em língua portuguesa, os textos literários traduzidos são ainda mais escassos, uma vez que o pouco que se exporta do Haiti é destinado a países francófonos, logo, mantém-se em língua francesa. De acordo com Moreira (2011, p.234), "no Haiti, onde a grande maioria da população é analfabeta, houve pouca penetração da cultura europeia, e com isso uma maior preservação da cultura popular”, o que justifica a riqueza imbricada nos contos populares.

No que concerne aos contos populares, evidencia-se a quase inexistência de registros traduzidos a outras línguas (além do francês) deste rico patrimônio cultural. Em sua análise sobre literatura, história e cultura haitiana, Figueiredo (2006) esclarece que a 
literatura popular não prospera por ser transmitida em crioulo haitiano, entre aqueles que, em sua maioria, são analfabetos e não constituem um público leitor. É plausível conjecturar que tais contos, propagados oralmente e pouco preservados no meio escrito, podem desaparecer devido à crescente migração dos nacionais haitianos, considerada uma diáspora. Para tanto, almejamos que tal literatura seja conhecida, pois a voz dos próprios imigrantes é um veículo de divulgação da sua cultura aos países para os quais migram, como o Brasil. A partir do contexto de ensino, explicitamos a proposta:

\section{CONTEXTO DE CRIAÇÃO DE UM PROJETO DE ENSINO DO PORTUGUÊS BRASILEIRO PARA IMIGRANTES HAITIANOS}

O Projeto de Contação de Histórias Rakonte Mwen surge como um aprimoramento na prática de ensino, guiado pela pesquisa-ação, método de investigação em que o professor é também pesquisador do seu espaço docente. O desenvolvimento do Projeto é sustentado pela premissa de que aprendizes refugiados, ou em condição similar a do refúgio, como é o caso dos haitianos, necessitam de um ensino de línguas pela perspectiva do acolhimento, diferenciado daquele oferecido ao público estrangeiro geral. Maria José dos Reis Grosso (2010) determina que este ensino acolhedor interliga-se a um diversificado saber que exige a partilha e a compreensão de aspectos culturais dos que chegam e daqueles que os acolhem, para além do conhecimento linguístico. Neste viés, consideramos que a literatura popular vai ao encontro das necessidades de aprendizagem específicas.

O contexto de ensino é o curso de extensão da Universidade Federal da Fronteira Sul "Português para Estrangeiros", existente desde o início de 2014. As aulas são ministradas por graduandas em Letras Licenciatura- Português e Espanhol, da mesma instituição de ensino superior. Sua criação ocorreu a partir da necessidade de auxiliar haitianos acadêmicos da UFFS, bem como os demais haitianos da região que buscam aprender a língua portuguesa. Os alunos do curso de extensão apresentam nível de educação formal heterogêneo: alguns possuem nível superior completo, outros não concluíram o que equivale ao ensino fundamental brasileiro, porém, todos são alfabetizados. As turmas são divididas nos níveis Básico I, Básico II e Intermediário;

\footnotetext{
4 O curso é organizado em módulos semestrais, com duração de 50h por módulo, divididas em aulas de 3h, ministradas semanalmente aos sábados à tarde.
} 
esta divisão é feita no início de cada semestre, quando ocorre a abertura de novas turmas, através de questionário, sendo este o instrumento que nivela os estudantes recémingressos, além de breve entrevista oral. De acordo com o grau de conhecimento prévio da língua portuguesa e dos objetivos de aprendizagem, os estudantes são encaminhados para uma das turmas.

Desenvolvemos o projeto Rakonte Mwen na turma do nível intermediário, destinada aos imigrantes que já são capazes de responder as perguntas do questionário feitas em língua portuguesa, vivem no Brasil há mais de um ano e àqueles que estão inseridos em espaço de ensino formal, ou desejam inserir-se. No segundo semestre de 2016, o grupo era constituído por 14 estudantes haitianos: 12 homens e duas mulheres, com idade entre 22 e 45 anos. Todos eram alfabetizados e 6 deles estavam inseridos em espaço formal de educação ( 5 no ensino superior, Universidade Federal da Fronteira Sul; 1 no ensino profissionalizante, Instituto Federal de Santa Catarina). Trabalhamos em duas professoras ${ }^{5}$ por turma no curso Português para Estrangeiros; no caso específico do desenvolvimento do $\mathrm{PCH}$, a segunda professora atuou como auxiliar durante as atividades de escrita e pesquisa que os alunos realizaram em sala.

Como postula David Tripp (2005, p.454), que teoriza sobre o método investigativo da pesquisa-ação, não é possível prever a maneira que os participantes responderão ao projeto, pois depende "de seus interesses e capacidades, relativamente a diferentes aspectos de um projeto, em diferentes épocas e lugares". No entanto, a ideia de trabalhar com contos populares surgiu a partir da aceitabilidade dos alunos. Nos semestres anteriores foram desenvolvidos trabalhos isolados com o gênero conto popular, resultantes em atividades proveitosas, fato que estimulou o trabalho docente ${ }^{6}$.

Ao final do PCH aplicamos questionário aos alunos para obter feedback em relação à relevância do Projeto no processo de acolhimento através da aprendizagem da língua portuguesa. Desde a primeira aula foi deliberado o produto final a ser produzido pelos alunos, que consistiu em um blog compilando informações sobre o Haiti, principalmente contos populares, escolha feita em conjunto entre professor e aluno. Nos

\footnotetext{
${ }^{5}$ Uma das professoras, autora deste artigo, é graduanda em Letras Licenciatura- Português e Espanhol e leciona no curso Português para estrangeiros desde sua criação, em 2014; a segunda professora do curso de extensão atuou no projeto em 2016 e também é graduanda em Letras. A outra autora deste artigo, professora doutoranda, coordenou e supervisionou a aplicação do projeto Rakonte Mwen.

${ }^{6}$ Para informações complementares sobre o curso Português para Estrangeiros da UFFS, consultar o artigo Curso de português para imigrantes haitianos: desenvolvimento cronológico, mudanças e reflexões. Mandinga, v. 1, p. 89-101, 2017 (SOARES, L. F.; TREVISAN, C. ; FLAIN, A. L. G.)
} 
termos da Pedagogia de Projetos, a função do produto final é de materializar o percurso de aprendizagem dos estudantes para que, ao fim de um ciclo de estudo, motivem-se por ter um resultado palpável das atividades realizadas (CAMPS, 1996). Na continuidade, trazemos os resultados da aplicação.

\section{PROJETO DE CONTAÇÃO DE HISTÓRIAS RAKONTE MWEN: RESULTADOS} DA PROPOSTA DIDÁTICA

\section{Aplicação: introdução ao estudo da literatura popular}

$\mathrm{O}$ PCH iniciou na quarta aula do curso "Português para Estrangeiros", que tem duração total de 50h. As primeiras três aulas foram reservadas à retomada dos conteúdos dos semestres anteriores, que envolviam os gêneros biografia, avisos, recados, notícias e reportagens ${ }^{7}$. Na primeira aula do Projeto (quarta aula do curso) os alunos elaboraram cartazes, em grupos, sobre os objetivos de aprendizagem do semestre e iniciativas individuais necessárias para alcançá-los. Esta ação inicial permitiu que refletissem sobre o comprometimento demandado para participar efetivamente do curso.

Durante a segunda parte da aula, discutimos sobre o Projeto de Contação de Histórias e foi feito acordo sobre o produto final, um blog para divulgar a cultura haitiana. Este trabalho foi introduzido por atividade de sensibilização, necessária ao se ensinar uma língua de acolhimento, através da discussão, em formato de perguntas, de reportagem acerca do Haiti, transmitida em rede nacional ${ }^{8}$. Os estudantes apontaram que a mídia manipulou a imagem do Haiti, a fim de depreciá-lo, pois a reportagem mostra uma favela da capital e afirma tendenciosamente que todo o país se encontra na mesma situação calamitosa. Na sequência, um segundo vídeo feito pelos imigrantes haitianos de Curitiba foi assistido e comentado, este apresentando resposta à reportagem, posicionamento em consonância ao dos estudantes ${ }^{9}$.

As respostas obtidas pelos estudantes do curso surpreenderam-nos positivamente devido à capacidade de argumentação, pois os estudantes pontuaram que

\footnotetext{
7 Os alunos do curso "Português para Estrangeiros" podem ingressar em qualquer um dos três níveis do curso. Há aqueles que iniciam no nível Básico I e prosseguem até o Intermediário, por este motivo realizamos atividades de revisão, visto que três estudantes pertenciam ao nível Intermediário II no semestre anterior.

8 Reportagem do apresentador Luciano Huck em viagem ao Haiti; disponível em: https://www.youtube.com/watch?v=fbwB6epAqSk Acesso em ago. 2016

${ }^{9}$ Disponível em: <https://www.youtube.com/watch? $\mathrm{v}=\mathrm{rKp} 5 \mathrm{LDeKero} \& \mathrm{t}=12 \mathrm{~s}$ >
} 
incontáveis países possuem lugares tomados pela miséria, inclusive aqueles considerados de primeiro mundo, não somente o Haiti. Para desvalidar o conteúdo da reportagem sobre o Haiti, os estudantes argumentaram que o Brasil reforça a imagem negativa do país caribenho a fim de manter suas tropas no país e, assim, ter visibilidade mundial. Surgiu a opinião unânime de que o país possui belezas naturais e rica cultura com raízes africanas. A reflexão dos alunos foi ao encontro da proposta do projeto e da finalidade do blog: divulgar a cultura haitiana a fim de desconstruir a imagem estigmatizada que os brasileiros têm do "país devastado pelo terremoto". Por meio de sugestão e votação da turma, o nome do blog foi definido como Rakonte Mwen: Kilty Lakai, em português, "Conte para mim: cultura da minha terra".

Para iniciar o trabalho com a literatura popular, perguntas indutivas sobre o gênero foram feitas relativas às histórias populares ouvidas na infância e contos universais estudados na escola. As respostas apontaram para fábulas de La Fontaine, contos dos irmãos Grimm e contos populares com os personagens Bouki et Malice ${ }^{10}$. Após os questionamentos, trabalhamos com o conhecimento prévio dos alunos acerca dos contos populares brasileiros, especificamente daqueles com o personagem Pedro Malasarte, devido a semelhança com os contos haitianos de Bouki et Malice. Como não o conheciam, foi oferecido subsídios para a construção do conhecimento, através de imagens e breves explicações, de acordo com os conceitos de Solé (1998), baseados na aprendizagem em momentos de pré-leitura, concomitante e posteriores ao ato de ler. Dessa forma foi construído o conhecimento prévio necessário para a compreensão do conto "A árvore que dava dinheiro" ", através do enriquecimento do repertório lexical por meio de imagens.

Para complementar o trabalho de acolhimento e sensibilização sobre o gênero, aplicamos o jogo do telefone sem fio, a fim de justificar as mudanças que ocorrem durante a transmissão dos contos orais. Apesar de a turma ser composta exclusivamente por adultos, todos se envolveram na dinâmica e compreenderam seu objetivo, refletindo conscientemente sobre como acontece a difusão oral de histórias. Em seguida, realizamos a contação da história de Malasarte, com subsídio de imagens e objetos para representala. Na sequência, houve a discussão sobre o conto narrado pela professora, momento em

\footnotetext{
${ }^{10}$ Os contos de Bouki et Malice são amplamente difundidos na literatura popular do Haiti, inclusivamente em contextos de educação formal como nas escolas, de acordo com os nacionais haitianos. Bouki é taxado como ingênuo, o "bobo", e Malice é o personagem malandro, que premedita suas ações com a finalidade de tirar proveito das situações, muitas vezes para garantir sua sobrevivência.

${ }^{11}$ Por se tratar de um conto popular, baseamo-nos em versão disponível online e fizemos adaptações. Disponível em: < http://www.recantodasletras.com.br/contos/1049695> Acesso em ago. 2016
} 
que os estudantes relacionaram os personagens brasileiros e haitianos, Malasarte e Malice, apontando as semelhanças de suas ações e personalidades.

A atividade de resumo foi utilizada para a compreensão pós-leitura (SOLÉ, 1998). Os alunos presentes na aula dividiram-se em grupos e cada um ficou responsável pela escrita de uma parte do conto, a constar, início, meio e fim. Anteriormente à contação, explicitamos que a atividade posterior, de resumo, seria produzida, uma vez que é necessário estabelecer com os alunos os objetivos dos textos estudados e as atividades que serão solicitadas. Segundo Solé (1998, p.93), o objetivo da leitura, neste caso, da compreensão de um texto contado oralmente para produção posterior de um resumo, determina como o leitor se situa frente ao texto. O objetivo também tem relação com o tipo e com o gênero textual, neste caso, tipo predominantemente narrativo do gênero conto popular. O resumo foi elaborado em sala, em grupos, e corrigido pela professora em momento extraclasse. A adequação ao gênero foi critério de avaliação principal, a partir dos seguintes aspectos: Há marcação dos personagens? Há sequência das ações? Há discurso direto? Desvios gramaticais, de coerência e coesão, também foram apontados na correção escrita que foi feita através do seguinte esquema de legendas:

- PONTUAÇÃO- sublinhado simples

"Caminhou por muito tempo: quando avistou uma árvore. Chegando ao pé da árvore (...)"

"Eu comprei arroz__ banana_leite__pão e ovos no mercado"

- ACENTUAÇ̃̃O/ORTOGRAFIA- circulado

"Caminhou por muito tempo, quando avistou uma arvore Chegando ao pé da rrvore(...)"

- REG $\hat{E} N C I A / C O N C O R D \hat{A N C I A}$ - sublinhado duplo

"Ele caminharam por muito tempo "; "Ele chegou no árvore"

- COESÃO/COER̂ENCIA- colchete [ ]

"[Ele caminhou uma árvore chegou até]; [Ele ir no mercado ontem];"

- REPETIÇÃO/REDUNDÂNCIA-parêntese ( )

("Malasarte caminhou por muito tempo e então Malasarte avistou uma árvore. A árvore era muito grande. Malasarte chegou ao pé da árvore") 
$\mathrm{Na}$ aula seguinte, os alunos receberam suas produções dos resumos corrigidas através do esquema de legendas, para então realizar a segunda versão. Esta forma de correção foi pensada para que os estudantes refletissem sobre os desvios apontados e angariassem a ajuda da professora quando necessário, contudo, deveriam ser proativos e consultar a internet e dicionários no momento da correção. Os alunos que haviam faltado na aula anterior foram distribuídos entre os grupos para que os colegas explicassem o que haviam estudado, concedendo espaço de autonomia aos aprendizes (CAMPS, 1996). Cabe observar que o cronograma inicialmente planejado precisou ser readaptado, visto que as atividades de produção escritas passaram a ser realizadas em sala, pois os estudantes não dispunham de tempo para realizá-las em casa. As versões reescritas em sala, a partir da correção via legendas e da ajuda das professoras, apresentaram-se mais coesas e coerentes que as primeiras produções, seguindo a ordem de início, meio e fim da história com encadeamento dos fatos narrados.

No segundo momento da aula 2 do projeto, os alunos tiveram acesso ao conto escrito em sua versão original e, a partir dele, foram explicitadas as marcas da oralidade presentes na escrita, típicas dos contos populares, bem como os marcadores textuais, como palavras em negrito e itálico, além dos sinais de pontuação que indicam a reação dos personagens (SOLÉ, 1998). Também foi realizada atividade de leitura do conto popular brasileiro previamente contado e estudado, "A árvore que dava dinheiro". Durante a leitura não se interrompeu os estudantes, contudo, após a atividade oral, foram indicados os pontos a serem melhorados em relação à apresentação perante o público ouvinte e demais características da superestrutura do gênero que conduzem a oralização do que está escrito como, por exemplo, diferenciação de entonação entre a fala dos personagens e do narrador. Desvios de pronúncia também foram indicados, centrados na correção da sílaba tônica das palavras e da prosódia do português brasileiro.

Ao avaliar o ato de leitura do conto acreditamos que foi pertinente, pois, como indicado por Solé (1998), os estudantes devem se sentir capazes de realizar uma tarefa solicitada pelo professor. A turma já possuía conhecimento sobre o conto, previamente "contado", resumido e lido. De acordo com a autora, a leitura em voz alta não comprova a compreensão do texto, por este motivo, a ação oral foi complementar ao trabalho de compreensão do gênero literário em questão e do seu enredo. A continuidade da primeira etapa do projeto, cujo objetivo era conhecer o gênero conto popular, se deu através do 
trabalho com o conto "Sopa de Pedra"12, em que o personagem principal também é Pedro Malasarte. O segundo conto popular brasileiro seguiu as etapas de atividades similares ao primeiro e possibilitou a melhor compreensão das características do gênero literário e do tipo textual narrativo, bem como o aprimoramento do ato de contar histórias. Em seguida, apresentamos a aplicação da segunda etapa do $\mathrm{PCH}$, que consistiu na produção oral e escrita de contos populares haitianos:

\section{Produção oral e escrita dos contos populares haitianos}

Na segunda etapa do projeto, os alunos já compreendiam satisfatoriamente as características do gênero conto popular, competência verificada anteriormente, através das atividades com dois contos populares brasileiros. Ao iniciar o trabalho com a literatura popular haitiana, 4 grupos foram estrategicamente indicados para a distribuição de alunos com frequência regular. Para acompanhamento dos resultados de ensino, baseado nas propostas de Ohlweiler (2006), autora que utilizou a Pedagogia de Projetos no ensino do português como língua não materna, avaliamos o progresso dos alunos no que se refere ao domínio da língua alvo através de produções orais e escritas. Foram produzidas no mínimo duas versões de cada conto popular haitiano no código escrito e oral, para que fosse possível observar a evolução ocorrida a partir da produção inicial. Sugerimos que a fonte do conto fosse a memória pessoal, por isso as professoras auxiliaram individualmente cada grupo na escolha das histórias. Contudo, no momento de produzi-los, havia muita divergência entre os alunos e não havia acordo quanto aos contos a serem trabalhados em cada grupo, que deveria ser em conjunto entre os integrantes.

Para viabilizar as atividades, selecionamos contos haitianos em momento anterior à aula, material de apoio que só seria utilizado se necessário, prevendo o caso de alunos que não recordassem nenhum conto popular. Os contos, pertencentes ao site

\footnotetext{
${ }^{12}$ Por se tratar de um conto popular, baseamo-nos em versão disponível no livro Contos populares para crianças da América Latina. São Paulo: Ática, 2000. Co-edição latino-americana. p. 8-15. A partir deste texto, fizemos modificações.
} 
"conte-moi"13, são histórias populares coletadas e compiladas, disponíveis em francês. Traduzimos para o português, anteriormente à aplicação do Projeto, os contos "Les oeufs de la cane Calandéric", "Monplaisir", "Janot, le cuisinier du roi" e "L'enfant Crapaud et Simbi", disponíveis no site. Cada grupo escolheu um dos contos, escritos em francês ${ }^{14}$, e realizou a leitura. Em seguida, a turma ouviu o áudio da contação das história, em francês e em crioulo haitiano (também disponível no site "conte-moi"), atividade de compreensão auditiva que foi complementada por discussão guiada pela professora. Os aprendizes relataram ter ouvido histórias parecidas, com enredo idêntico ou semelhante, principalmente aquelas com os personagens Bouki et Malice, presentes nos contos "Monplaisir" e "Les oeufs de la cane Calandéric".

Os contos em francês foram utilizados como base pelos estudantes, buscando compreendê-los e expressá-los em português a partir de sua leitura e debate entre os grupos. Esse viés inesperado, em que textos pré-existentes embasaram a escrita dos contos haitianos, possibilitou uma nova reflexão para o Projeto, ao pensarmos na intercompreensão existente entre línguas românicas (caso do português, espanhol, francês, italiano e também do romeno). Nessa perspectiva, o fato de que os estudantes se encontram no nível intermediário e têm, além do crioulo e francês, o espanhol presente em sua vivência elou memória linguística, estes podem desenvolver estratégias de compreensão e aprendizagem em outras línguas da mesma família.

Além do texto-base em língua francesa, foi construído juntamente aos alunos os principais aspectos estruturais do gênero conto popular, tipos textuais narrativo e descritivo. Assim, através de esquema repassado pela professora, os alunos puderam verificar se seus contos atendiam às exigências prescritas, relativas aos personagens e sua descrição, ao espaço dos acontecimentos, conflito da história, ações principais para resolvê-lo e desfecho. Os estudantes utilizaram como suporte a página conte-moi, que disponibiliza contos haitianos em francês e crioulo.

Acerca da primeira versão dos contos escritos, percebemos que os alunos seguiram a estrutura do gênero conto popular e as produções ficaram coerentes. Como

\footnotetext{
13 Site que disponibiliza contos populares de países francófonos. Disponível em: http://www.contemoi.net/ Acesso em mai.2016
}

\footnotetext{
${ }^{14}$ Apesar do francês ser idioma oficial no Haiti, parcela significativa da população tem o crioulo haitiano como única língua (CONTINGUIBA; CONTINGUIBA, 2014), logo, nem todos os haitianos falam francês. No entanto, na turma em que aplicamos o PCH todos os estudantes tinham o francês como segunda língua ou eram bilíngues (francês e crioulo), informação obtida através do questionário inicial do curso de extensão.
} 
exemplo, a seguir apresentamos excertos das produções, com a correção através do esquema de legendas; a transcrição dos fragmentos contempla alguns dos desvios recorrentes nas produções escritas:

\section{Grupo 1}

"[...]Monplaisir, o bode

_O rei (ele) chorava a disparição do seu animal preferido um bode que (ele) chamava Monplaisir. (Ele) [promete uma fortuna que consegue] lhe dar esclarecimento sobre o desaparecimento. [Em a] verdade o Malice foi ocupado. (Ele) [matou o bode, decepa.] $[\ldots] "$

\section{Grupo 2 \\ "[...]Bouki et Ti Malice}

_Tio Bouki desceu à cidade para o mercado, para vender alguns inhames, e [enquanto (ele) está lá (ele) ficou] com fome. (Ele) viu um homem velho de cócoras ao lado da estrada, comendo alguma coisa. [...]"

\section{Grupo 3}

"[...]Tezen

__Uma (mãe) tinha um [casual]__

sepre) que (a mãe) mandava a filha buscar água numa [mina de água] ela sempre trazia água limpa. Quando o filho ia buscar, ele pegava água suja_

[...] Tezen era um peixe que morava [na aquela] [mina], quando a filha cantando, aparecia (o peixe) e conversa com ela, e (o peixe) deixou ela pega đgualimpa. [...]”

Para o aprimoramento dos textos, elaboramos um relatório de desvios ${ }^{15} \mathrm{em}$ relação ao gênero e às questões gramaticais, a partir da primeira produção escrita dos grupos. Como havia um texto base para a produção escrita do conto, a superestrutura do gênero foi mantida, com início, meio e fim demarcados, encadeamento dos

${ }^{15} \mathrm{O}$ presente artigo centrou-se em apresentar os resultados gerais do Projeto de Contação de Histórias, bem como suas principais etapas. Devido a este enfoque, condensamos os relatórios de desvios dos contos escritos e orais produzidos pelos alunos. 
acontecimentos, ações realizadas pelos personagens coerentemente e trechos de discurso direto, contudo, destacaram-se desvios no emprego dos tempos verbais, presente na maioria das produções. Explicamos aos alunos que o tempo verbal em que acontecem os fatos narrados deve seguir uma linha lógica para representar a sequência dos acontecimentos.

Visto que a primeira correção se centrava nos aspectos estruturais do gênero conto popular, adequação cumprida em todas as produções, pontuamos as inadequações superficiais no que se refere a um texto no código escrito: falta de parágrafo, falta do travessão para indicar discurso direto e falta de pontuação. As construções não usuais na língua portuguesa que se relacionam diretamente a compreensão do interlocutor foram indicadas como problema de coerência, entre colchetes, segundo a legenda de erros. Também corrigimos a falta de coesão e repetição das palavras, principalmente dos pronomes pessoais. Explicamos que na língua portuguesa é possível suprimir o sujeito explícito indicado por pronome pessoal, como nos casos em que o pronome "ele" é repetido sem necessidade, em amostra das produções. Esses aspectos foram o foco da correção, para que, posteriormente, os estudantes fizessem a adequação dos demais elementos do texto, como desvios relacionados à ortografia e aprimoramento do conto.

Sobre os desvios gramaticais, observamos que há interferência do espanhol no código escrito. Os estudantes relataram que muitos haitianos alfabetizados têm noções básicas do espanhol, devido à proximidade do país com a República Dominicana. Isso justificaria as marcas de interferência encontradas nas produções textuais, mesmo daqueles que não viveram no país hispano falante. Outro desvio frequente, possivelmente causado pela interferência da língua espanhola, foi a contração de artigos e preposições (por exemplo, o registro da oração "Em a", ao invés de "Na”), o que motivou a explicação do tópico "artigos e preposições: contrações" em sala.

Durante a reescrita da primeira versão, os alunos tiveram dificuldade em interpretar as legendas, então auxiliamos com explicações individuais, retomadas de acordo com suas respectivas marcações. Percebemos, através desta experiência, que é necessário explicitar informações adicionais sobre os tipos de erros cometidos, além de limitar a correção a, no máximo, dois símbolos de legenda, para melhor situar os aprendizes e estabelecer quais os elementos mais importantes a serem corrigidos.

Na segunda versão da produção escrita, os desvios foram sinalizados, comentados e explicitados, no corpo do texto e ao seu final, dando ênfase à adequação linguística do 
gênero conto popular, através de comentários escritos por extenso. A seguir, exemplos, retirados da segunda versão das produções reescritas:

\section{Grupo 1}

\section{“[...]Monplaisir, o bode}

O rei chorava o desaparecimento do seu animal preferido: um bode que se chamava Monplaisir. Ele prometeu uma fortuna se alguém conseguisse lhe dar esclarecimento sobre o desaparecimento. Na verdade [o Malice foi o culpado.

Lembre-se das palavras que unem as frases, para que seu texto não fique cheio de pontos finais. Tente substituir aqui por uma dessas palavras (em seguida, então...)

O Malice] matou o bode e cortou em pedacinhos pra comer a carne e usar a pele. [...]”

\section{Grupo 2}

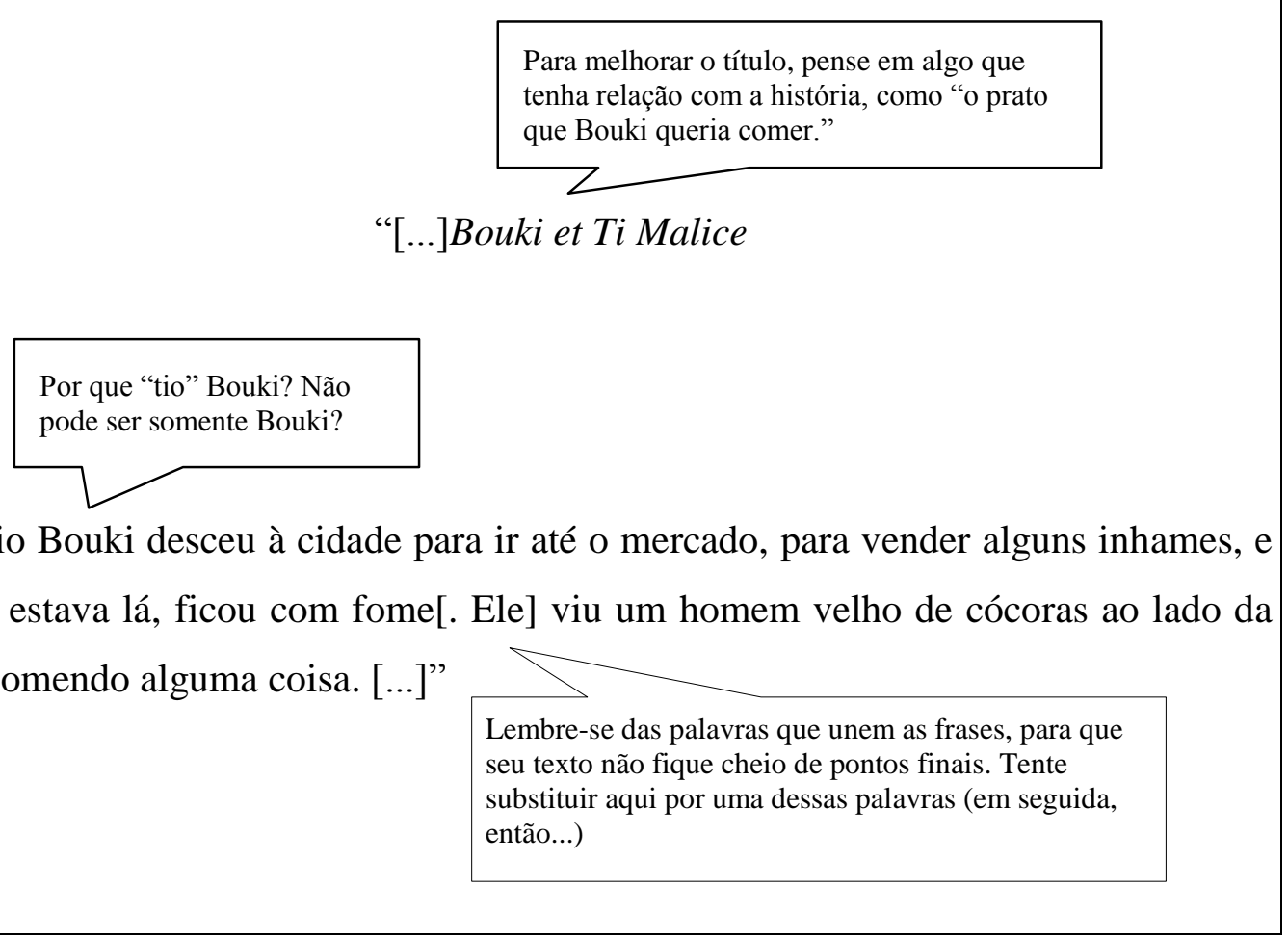




\section{Grupo 3}

\section{“[...]Tezen}

\section{Parágrafo}

$$
\text { 乙 }
$$

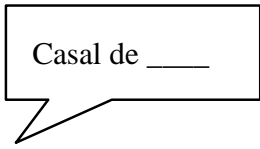

_Uma mãe tinha um casal e sempre que mandava a filha buscar (água) numa fonte de (água), ela sempre trazia (água) limpa. Quando o filho ia buscar, ele pegava (água) suja

[...] Tezen era um peixe que morava naquela fonte de água, quando a filha cantava, o peixe aparecia para conversar com ela e deixa pegar água limpa.[...]"

No relatório de desvios da segunda versão escrita foi recorrente a repetição dos mesmos conectores textuais ou sua supressão, o que se classifica como desvios de coesão. Para auxiliar os estudantes, disponibilizamos uma breve lista com os principais conectores textuais e sua finalidade. Chamamos a atenção à questão da autoria do texto, destacamos que qualquer fonte consultada para a produção do conto deve ser explicitada, seja site da internet ou livro. Com a melhor explicação dos desvios cometidos, através de comentários escritos no texto, a melhoria nas produções foi significativa. Além disso, a professora escreveu ao fim de cada texto pontos que poderiam ser melhorados, visando o aperfeiçoamento de conto popular. Foram eles:

(a) Lembra dos contos de Pedro Malasarte? Reveja as expressões que são usadas nas falas dos personagens (nossa! Puxa vida!).Tente acrescentar algumas expressões no seu conto, principalmente onde há o discurso direto.

(b) Para seu texto ficar ainda melhor, faça referência ao lugar onde ele é contado, como nos contos de Malasarte (Lá no sertão, no interior, vivia um sujeito chamado Malasarte...) 
(c) Para o texto ficar compreensível, precisa ter um final coerente, que faz sentido. Localize o final do seu conto e veja se está bom ou se pode ser melhorado

(d) Evite unir as frases com pontos finais, procure utilizar a lista de conectores, assim seu texto fica mais coerente e coeso. Não repita SEMPRE os mesmo conectores (então, então, então....).

A partir da segunda reescrita dos contos, foi proposta atividade oral. Primeiramente, os grupos dividiram o texto em início, meio e fim, em que cada integrante era responsável por produzir uma das partes. Em seguida, houve a prática leitora dentro de cada grupo, momento em que as professoras anotaram o que poderia ser melhorado para o ato de contação da história. Posteriormente, os alunos receberam um roteiro para guiar a contação, a fim de explicitar os elementos importantes na produção de um texto oral condizente ao gênero conto como: tom de voz; pausa para o ouvinte assimilar o conteúdo; expressão facial e corporal; elementos de abertura e fechamento como título e explicação sobre a fonte de leitura. Depois de os ajustes serem feitos, cada grupo apresentou seu conto para o restante da turma em espaço ao ar livre. Alguns preferiram utilizar o texto como suporte, caso esquecessem alguma parte.

A ação resultou em atividade proveitosa, porém, aproximou-se à leitura em voz alta, uma vez que a leitura do texto escrito deixa os estudantes mais seguros. Durante a contação, as professoras elaboraram relatório de desvios orais, os quais foram discutidos em sala. Dentre os apontamentos, destacamos: a não apresentação do título do conto; falta de ênfase ao expressar as emoções dos personagens (surpresa, raiva, felicidade); tom de voz muito baixo para ser compreendido e inexistência de contato visual com o público. Os desvios de pronúncia incidiram sobre o equívoco da sílaba tônica das palavras e a prosódia do português brasileiro

Na sequência, o resultado da terceira versão dos contos produzidos pelos alunos, fragmentos analisados anteriormente:

\section{Grupo 1}

“ [...]Monplaisir, o bode

O rei chorava o desaparecimento do seu animal preferido: um bode que se chamava Monplaisir. Ele prometeu uma fortuna se alguém conseguisse lhe dar esclarecimento sobre o sumiço do seu querido animal. Na verdade o malandro do Malice foi o culpado porque matou o bode, picou em pedacinho, comeu a carne e usou a pele pra fazer roupa.[...]" 
Grupo 2

\section{"[...]O prato que Bouki não comeu}

Bouki, o bobo, desceu à cidade para ir até o mercado, para vender alguns inhames, e enquanto estava lá ficou com fome. De repente, viu um homem velho de cócoras ao lado da estrada, comendo alguma coisa que parecia gostosa. [...]"

\section{Grupo 3}

"[...]Tezen

Em um lugar do Haiti, no interior do país, uma mãe tinha um casal de filhos que ajudava a cuidar da fazenda. Sempre que mandava a filha buscar água na fonte, ela trazia água limpinha, mas seu filho trazia água suja e não servia nem para lavar o chão.

[...] Tezen era um peixe que morava na fonte. Quando ouvia a canção aparecia para conversar e deixava pegar a água limpa que ficava no fundo. [...]”

A partir das três versões produzidas, é evidenciada a progressão dos estudantes no domínio da língua portuguesa. As amostras das produções escritas e os sumários dos relatórios de desvios apresentam a evolução no domínio do código escrito, de acordo com os aspectos gramaticais, sintáticos e estruturais do gênero conto popular. Após a produção da terceira versão escrita, versão final após as correções via esquema de legendas feitas pela professora, os contos populares também foram narrados às demais turmas do curso "Português para Estrangeiros", em sarau organizado pelos próprios estudantes. Este momento cultural e de integração entre as demais turmas do curso, foi registrado em vídeo que integra o material do blog. A seleção de fotos e vídeos para integrar a página da internet foi desenvolvida em sala de aula, com a participação dos estudantes. Nesta etapa final, conhecimentos secundários foram mobilizados, a fim de organizar o layout do blog, criar um domínio para a página, organizar a sequência das imagens e digitalizar os contos populares produzidos.

Ao final do projeto, aplicamos questionário a fim de que os alunos avaliassem seu aprendizado e os pontos mais relevantes do trabalho desenvolvido. Em análise sucinta dos questionários, as respostas destacaram que conhecer uma nova língua permite interagir melhor com a cultura de um país, para além das relações cotidianas básicas; também salientaram que para "fazer a diferença" em um país é necessário dominar a 
língua que a maioria das pessoas fala, pois só assim é possível conhecer os direitos e deveres individuais, além de reclamar quando não são cumpridos. Sobre o momento mais relevante do trabalho, os estudantes apontaram as ações registradas em vídeo, pois este diferencial motivou-os a estudarem o tema, visto que o material estaria disponível na internet, em que todos podem acessar. As respostas também revelaram que a contação das histórias populares brasileiras, com objetos, imagens e narração da professora, foi proveitosa, ao propiciar momento de aprendizagem diferenciado e "feliz".

Por fim, apresentamos o produto final do $\mathrm{PCH}$, idealizado a partir de etapas sequenciais do Projeto $^{16}$. Por se tratar de uma página na internet, ressaltamos a facilidade de divulgação para o público. Algumas produções que estão no blog não são analisadas neste trabalho, pois constituíram atividades extraclasse, logo, nem todos os estudantes as realizaram. Estas atividades são: Pontos turísticos do país, Estações do ano e a lenda do herói Mackendal. No blog há também seção destinada à breve descrição pessoal de cada aluno, não pensada no planejamento do Projeto, criada a partir de solicitação dos estudantes. A partir da descrição e análise das etapas de aplicação, sistematizamos os resultados a fim de contrapô-los aos nossos questionamentos e hipóteses iniciais:

O blog produzido ao final do Projeto de Contação de Histórias cumpriu com o seu objetivo inicial de divulgar a cultura haitiana aos brasileiros e de inserir os estudantes como sujeitos atuantes no processo de aprendizagem, uma vez que eles foram os responsáveis pela idealização do produto final. Para isso, os alunos mobilizaram seus conhecimentos secundários, relacionados à montagem da página, edição de fotos, organização dos elementos suprassegmentais de uma página da internet e gravação de vídeos. A autonomia dada aos estudantes foi fundamental para a concretização do Projeto, como prevê a Pedagogia de Projetos (CAMPS, 1996).

Além disso, a contribuição dos aprendizes no curso das ações foi tão ativa que o trabalho com as lendas de zumbis e com os deuses vodus foi excluído, devido à solicitação unânime da turma. Cabe expor que o trabalho com a religião vodu foi motivado a partir de conversas informais com haitianos, estudos que abordam questões culturais do Haiti (FIGUEIREDO, 2006) (CONTINGUIBA; CONTINGUIBA 2014) e o livro do autor haitiano Dany Laferrière (2011). A não identificação dos alunos com a religião vodu foi de encontro a nossa pressuposição inicial de que esta é uma religião amplamente difundida entre os nacionais haitianos, ponto passível de pesquisa sobre o

\footnotetext{
${ }^{16}$ Blog disponível em:< http://portuguesuffs.wixsite.com/culturadohaiti >
} 
vodu, o qual, conjecturamos, está relacionado às regiões do país, idade e condição sociocultural dos sujeitos.

No produto final o grupo também produziu atividades não planejadas inicialmente, como exemplo, a descrição pessoal e o relato sobre pontos turísticos do país, bem como prevê a metodologia de análise da pesquisa-ação, ao definir que "os resultados de cada ciclo determinarão o que acontecerá a seguir e não há como dizer de saída aonde o processo levará" (TRIPP, 2005, p. 459). Visto a aceitabilidade do trabalho com a divulgação dos trabalhos na internet, o blog, vinculado ao curso "Português para Estrangeiros", será alimentado com atividades desenvolvidas nos semestres seguintes. Esta ação permanente possibilitará a divulgação da cultura haitiana, um dos objetivos deste trabalho.

Ao considerar que nem todos os alunos atendiam regularmente às aulas, concluímos que a dinâmica de grupos de trabalho contribuiu na integração dos estudantes. A falta às aulas e o perfil de estudantes trabalhadores assemelha-se àquele descrito por Ruano e Cursino (2015), em relação ao projeto "Português Brasileiro para Migração Humanitária- PBMIH" da Universidade Federal do Paraná. A metodologia de ensino deste contexto é descrita pelas autoras como "ensino em trânsito", em que o aluno inicia o curso em qualquer momento do semestre e cuja abordagem de ensino é por tarefas comunicativas. Apesar das semelhanças entre o público aprendiz do curso "Português para Estrangeiros" e do PBMIH, julgamos adequado trabalhar com projetos pedagógicos com o público específico do nível intermediário, composto por acadêmicos da UFFS e por haitianos que pretendem ingressar no ensino superior ou em cursos profissionalizantes. Nas turmas dos níveis básicos do projeto de extensão o ensino em trânsito seria mais adequado.

Mendes (2004) observa que uma abordagem de ensino intercultural é capaz de modificar as concepções de ensino-aprendizagem também dos professores que precisam "subverter" esquemas já enraizados em sua prática pedagógica. Ao pensar na experiência docente proporcionada pelo $\mathrm{PCH}$, pontuamos que o Projeto possibilitou contato mais humano e sensível com os estudantes, através dos momentos de contação de histórias e produção dos vídeos. O contato mais próximo com os aprendizes e o tema do Projeto contribuíram com o aprendizado docente sobre a cultura haitiana, ao demonstrarmos para os alunos interesse sobre sua cultura, fomentando o diálogo sobre este tema e proporcionando o fluxo de conhecimento entre professor-aluno. Este aprendizado também é útil a nível pessoal e profissional, pois o professor adquire conhecimento e 
experiência que podem ser empregados na formulação de novos projetos didáticos no ensino à comunidade de imigrantes e/ou refugiados.

\section{CONSIDERAÇÕES FINAIS}

Concluímos esta proposta de ensino com resultados de aprendizagem dos alunos que corroboram com a afirmação de que um trabalho estruturado pela literatura popular e pela abordagem intercultural é profícuo para imigrantes haitianos. As produções orais e escritas comprovam a evolução dos estudantes no que se refere ao domínio da língua portuguesa, devido ao trabalho linguístico contextualizado através de um gênero. Somado às produções orais e escritas dos alunos que sustentam essa assertiva, está a postura pedagógica do professor, que, ao assumir o papel de mediador, dá espaço para que o aprendiz contraponha elementos da sua cultura com elementos da cultura acolhedora para, então, compreender e se inserir no novo contexto social em que se encontra.

A aprendizagem do português brasileiro a partir do conceito de Língua de Acolhimento (GROSSO, 2010) e a abordagem intercultural no ensino de línguas (MENDES, 2004) explicam satisfatoriamente os resultados obtidos pelo Projeto de Contação de Histórias Rakonte Mwen, que direcionou o estudo do português para além do uso em relações pragmáticas do cotidiano, uma vez que trabalhamos com um gênero literário que se relaciona ao uso da língua como forma de fruição artística, fantasia (CANDIDO, 2002). Destacamos que a apresentação de narrativas orais, em forma de sarau e registro com vídeos, proporcionou momento de aprendizagem diferenciado e significativo, como foi apontado pelos estudantes no questionário final. Portanto, as atividades orais e escritas analisadas e a participação ativa dos estudantes denotam a significativa progressão e consciência nalda aprendizagem do público aprendiz, bem como sua maior motivação para estudar a língua mais falada no Brasil. Através da idealização do blog, foi possível divulgar a cultura do Haiti aos brasileiros, trabalhando na desconstrução da imagem negativa construída de "país mais pobre das américas".

Sobre os aprendizados propiciados pela docência com público de imigrantes haitianos, é patente o exercício de alteridade fomentado pelo ensino intercultural que permite ao professor ser um agente social no processo de desestigmatização sobre uma cultura e consequente enriquecimento cultural. Diante dos resultados obtidos, reafirmamos a importância do ensino pelo viés de acolhimento para imigrantes haitianos. 
As características acolhedoras do trabalho com a língua portuguesa se manifestam na relação professor-aluno, ao promover ações com perspectiva humana e sensível às necessidades dos aprendizes, adequações ínfimas que diferenciam o ensino acolhedor do tradicional. Outra constatação feita é de que o espaço dado à língua materna e às concepções de mundo dos aprendizes funciona como aproximador cultural, mesmo que seu domínio por parte do professor seja restrito ${ }^{17}$.

No que diz respeito aos métodos de correção e avaliação adotados, afirmamos que é interessante utilizar o esquema de legendas na correção das produções escritas, contudo, esta ferramenta deve ser introduzida paulatinamente, com um ou dois símbolos a cada versão do texto. Observamos que os estudantes precisam de tempo para se familiarizar ao método de correção. Ademais, os conceitos de compreensão leitora propostos por Solé (1998) permitiram que o gênero literário ultrapassasse sua função de fruição artística e também constituísse objeto de análise a aprendizado/estudo.

Pontuamos ser possível dar continuidade ao trabalho a partir de outros gêneros discursivos, futuro desdobramento do presente artigo. Outrossim, é oportuno ressaltar que este trabalho tem a pretensão de se desdobrar em material didático específico para nossos estudantes, a fim de inserir nossa Universidade no âmbito das mais recentes discussões, pesquisas e ações sobre o ensino de português a haitianos.

\section{REFERÊNCIAS}

Alto Comissariado das Nações Unidas para Refugiados (ACNUR). Pode Entrar: Português do Brasil para Refugiadas e Refugiados. Editor responsável: Talita Amaro de Oliveira. $1^{\text {a }}$ ed. São Paulo, 2015

AMADO, R.S. O ensino de português como língua de acolhimento para refugiados. Revista da SIPLE, Brasília, v.4, n. 2, s.p., out 2013. [online]

ANÇÃ, M.H. Português: língua de acolhimento: entre contornos e aproximações. In: CONGRESSO INTERNACIONAL SOBRE HISTÓRIA E SITUAÇÃO DA EDUCAÇÃO EM ÁFRICA E TIMOR. Lisboa. Anais... . Lisboa, Universidade Nova de Lisboa, Faculdade de Ciências Sociais e Humanas, 2003. p. 1-6.

CABETE, M.A.C.S.S. O processo de ensino-aprendizagem do português enquanto língua de acolhimento. Dissertação (Mestrado) - Universidade de Lisboa, Lisboa, 2010.

17 É necessário pensar no ensino contrastivo do português brasileiro e da língua materna dos imigrantes. Quando este não é possível, pode-se adquirir noções básicas da língua materna do aluno a fim de valorizar sua língua materna através de ações minoritárias, como fizemos no PCH. 
CAMPS, A. Proyectos de Lengua entre la teoría y la práctica. Cultura y Educación, n. 2, pp. 43-57, 1996.

CANDIDO, A. A literatura e a formação do homem. In: CANDIDO, A. Textos de intervenção. São Paulo: Editora 34, 2002. Pp. 77-92.

COTINGUIBA, M. L. P; COTINGUIBA, G. C. Imigração haitiana para o Brasil: os desafios no caminho da educação escolar. Revista Pedagógica, v.17, n.33, pp.61-87, jul/ dez. 2014.

FIGUEIREDO, E. O Haiti: história, literatura, cultura. Revista Brasileira do Caribe, v.6, n. 12,p p.371-395, jan./ jun. 2006.

GROSSO, M. J. R. Língua de acolhimento, língua de integração. Horizontes de Linguística Aplicada, v. 9, n.2, pp.61-77, 2010.

LAFERRIÈRE, D. País sem chapéu. São Paulo: Editora 34, 2011. Tradução e posfácio de Heloísa Moreira.

MENDES, E. Abordagem Comunicativa Intercultural (ACIN): uma proposta para ensinar e aprender lingua no diálogo de culturas. Tese (Doutorado) - Universidade Estadual de Campinas, Instituto de Estudos da Linguagem, Campinas, 2004.

MOREIRA, H. Prefácio. In: LAFERRIÈRE, D. País sem chapéu. São Paulo: Editora 34, 2011.

OHLWEILER, B.M.D. Criação de um jornal na sala de aula de português língua estrangeira. Dissertação (Mestrado) - Curso de Programa de Pós-graduação em Letras, Universidade Federal do Rio Grande do Sul, Porto Alegre, 2006.

PIMENTEL, M.L.; COTINGUIBA, G.C.; NOVAES, M.L.Lingua portuguesa para haitianos. Florianópolis: SESI/SC, 2014.

RUANO, B. P.; CURSINO, C. A. O ensino de português brasileiro como língua de acolhimento: projeto PBMIH-UFPR - um estudo de caso.. In: I Congresso Internacional de Estudos em Linguagem, 2015, Ponta Grossa. CIEL 2015- Anais completos, 2015

RUANO, Bruna P.; GRAHL, João Arthur . Portuguese as a welcoming Languageteaching experiences with Haitian and Syrian students from PBMIH-UFPR project. In: XXXIII International Congress of the Latin American Studies Association, 2015, San Juan. LASA 2015/Precariedades, exclusiones, emergencias, 2015. v. XXXIII.

SÁ, T. Lugares e não lugares em Marc Augé . Tempo Social: revista de sociologia da $U S P$, v. 26, n. 2 , pp. 209-229, nov. 2014

SOARES, L. F.; TREVISAN, C. ; FLAIN, A. L. G. Curso de português para imigrantes haitianos: desenvolvimento cronológico, mudanças e reflexões. Mandinga, v. 1, n.1, pp. 89-101, 2017.

SOLÉ, I. Estratégias de leitura. Porto Alegre: Artmed. 1998 
TRIPP, David. Pesquisa-ação: uma introdução metodológica. Trad. Lólio Lourenço de Oliveira. Educação e Pesquisa, v. 31, n. 3, pp. 443-466, set./dez. 2005. 